Article

\title{
Comparisons of Diurnal Variations of Land Surface Temperatures from Numerical Weather Prediction Analyses, Infrared Satellite Estimates and In Situ Measurements
}

\author{
Xiaoni Wang * and Catherine Prigent \\ L'Observatoire de Paris, Centre National de la Recherche Scientifique (CNRS), Paris Sciences et Lettres (PSL); \\ 75014 Paris, France; catherine.prigent@obspm.fr \\ * Correspondence: xiaoni.wang@obspm.fr
}

Received: 17 December 2019; Accepted: 1 February 2020; Published: 10 February 2020

check for updates

\begin{abstract}
This study evaluates the diurnal cycle of Land Surface Temperature (LST) from Numerical Weather Prediction (NWP) reanalyses (ECMWF ERA5 and ERA Interim), as well as from infrared satellite estimates (ISCCP and SEVIRI/METEOSAT), with in situ measurements. Data covering a full seasonal cycle in 2010 are studied. Careful collocations and cloud filtering are applied. We first compare the reanalysis and satellite products at continental and regional scales, and then we concentrate on comparisons with the in situ observations, under a large variety of environments. SEVIRI shows better agreement with the in situ measurements than the other products, with bias often less than $\pm 2 \mathrm{~K}$ and correlation of 0.99 . Over snow or arid surface, ISCCP tends to have more systematic errors than the other products. ERA5 agrees better to the in situ over barren land than ERA Interim, particularly at night time, thanks to the new surface model. However, over vegetated surfaces, both reanalyses tend to have higher/lower temperature at night/day time than the in situ measurements, probably related to the surface processes and its interactions with atmosphere in the NWP model.
\end{abstract}

Keywords: land surface temperature; satellite thermal infrared; seasonal and diurnal variations; in situ measurements

\section{Introduction}

Land Surface Temperature (LST) plays a key role in the land surface energy budget. It is the radiative skin temperature and shows large spatial variabilities due to strong surface heterogeneity. The seasonal and diurnal cycle of LST is influenced by solar insolation, atmospheric changes (e.g., cloud coverage), and surface characteristics. LST and its diurnal variation are useful for a wide variety of applications, for example the urban climate changes [1,2], land cover changes [3], land-atmosphere interactions [4-7], fire monitoring [8,9], and droughts and water managements [10] etc.

For over 40 years, LST has been estimated from satellite thermal infrared (TIR) observations, at a global scale, from both geostationary and polar satellites. They use single channel algorithms, or split-window algorithms with temperature and emissivity separation methods. For instance, the International Satellite Cloud Climatology Project (ISCCP) produces global LST (in addition to many cloud variables), since 1982, from a large collection of geostationary and polar satellites observing in the infrared [11]. A new version of the products, 3-hourly and at a spatial resolution of $\sim 10 \mathrm{~km}$, has recently been delivered [12], with a number of modifications applied. The EUMETSAT Land Satellite Applications Facility (Land SAF) also produces LST estimates from Spinning Enhanced Visible and Infrared Imager (SEVIRI) on board the geostationary satellite METEOSAT Second Generation, 
every $15 \mathrm{~min}$ with a spatial resolution of $3 \mathrm{~km}$ [13]. This covers the continents of Europe, Africa, a part of south America and of Asia. The TIR technique has the advantages of producing data with fine spatial resolution, however they are constrained by atmospheric and cloud contamination.

Numerical Weather Prediction (NWP) centers combine observations and modeling resources in assimilation schemes to provide weather forecast and climate data records [14]. ECMWF (European Centre for Medium-Range Weather Forecasts) produces the ERA series, with the latest ERA5 dataset providing hourly estimates of a large range of geophysical products (including LST), with an enhanced spatial resolution of $31 \mathrm{~km}$, since 1979 [15].

Several ground stations have been developed in response to the growing need for more in situ LST measurements for the validation of satellite observations and numerical models, and for climate and weather studies. NOAA's Surface Radiation Networks (SURFRAD) operate stations in the United States since 1993 [16]. Other permanent stations are run by the Karlsruhe Institute of Technology (KIT) [17]. These in situ measurements were used in several satellite validation studies [18-20].

In this work, we propose an evaluation of recently available LST datasets that sample the LST diurnal cycle (the new version of ISCCP and ERA5). Comparisons will also involve the Land SAF products from SEVIRI and in situ measurements. Data covering a full seasonal cycle in 2010 are selected. We will first evaluate model and satellite products at continental and regional scales, and then we will concentrate on comparisons with the in situ observations, under a large variety of environments. The paper is organised as follows. In Section 2 we present the datasets and their processing. In Section 3 , comparisons are performed between ECMWF, ISCCP, and SEVIRI LSTs, within the disk covered by SEVIRI. The data and their diurnal variations are further evaluated with ground-based measurements in Section 4. Conclusions are provided in Section 5.

\section{The LST Datasets}

\subsection{The ERA Reanalyses from NWP}

ERA5 is the latest European reanalysis that replaces the ERA Interim product. It includes several important improvements with a revised land surface hydrology (HTESSEL) [21]. The revisions to the soil hydrology include: (i) a spatially varying soil type replacing the single global soil texture, (ii) a different formulation of soil hydraulic properties, and (iii) the surface runoff changes based on soil type and local topography. In addition ERA5 offers higher temporal and spatial resolutions compared to ERA Interim, i.e., hourly versus 6-h, and $31 \mathrm{~km}$ in horizontal dimension versus $79 \mathrm{~km}$. The ERA5 data can be found at https:/ / cds.climate.copernicus.eu/cdsapp\#!/ dataset/reanalysis-era5-singlelevels?tab=overview, and here the ERA5 products have been downloaded gridded at $0.25^{\circ}$ spatial resolution. ERA Interim data are also used in this study, for comparison purposes, as many studies used this product so far. It is downloaded from http://apps.ecmwf.int/datasets/data/interim-full-daily, gridded at the same $0.25^{\circ}$ spatial resolution as ERA5.

\subsection{The Infrared ISCCP Satellite Product}

The International Satellite Cloud Climatology Project (ISCCP) produces a global, calibrated infrared and visible radiance dataset, along with information on the radiative properties of the atmosphere and surface [11]. The primary instruments used by ISCCP are the imaging radiometers onboard the AVHRR and several geostationary satellites. ISCCP products use visible (VIS around $0.65 \mu \mathrm{m}$ ) and infrared (IR around $10.5 \mu \mathrm{m}$ ) window channels to derive cloud and surface parameters. The surface temperature under clear-sky condition is retrieved by the inversion of radiative transfer equations. A recent version of the ISCCP product (the H-series) is provided by the National Climate Data Center of NOAA [12,22]. The data processing applies onboard target channel calibration and a sensor inter-calibration in order to produce multi-sensor radiance dataset. Compared to the former series (D-series), the H-series used improved atmospheric profiles, snow/ice cover fraction, surface type classification, and cloud detection scheme. The new data record is available 3-hourly 
and at $10 \mathrm{~km}$ spatial resolution (compared to $30 \mathrm{~km}$ before). The infrared emissivities adopted for the land surface temperature retrieval are fixed per surface types. The data are downloaded from http://https://www.ncdc.noaa.gov/isccp/isccp-data-access.

\subsection{The Infrared SEVIRI Satellite Product}

The LSA SAF produces LST from SEVIRI/MSG observation with view zenith angle ranging from $0^{\circ}$ to $80^{\circ}$ at temporal sampling rate of $15 \mathrm{~min}$, and a spatial resolution of about $3 \mathrm{~km}$ [13]. LST is obtained by correcting top-of-atmosphere radiances for surface emissivity, atmospheric attenuation, and downwelling radiations. It follows the generalized split window method developed by [23] for AVHRR and MODIS satellites, but adapted to SEVIRI response functions. The LST is estimated as a linear function of clear-sky top-of-atmosphere brightness temperature measured by SEVIRI at 10.8 and $12.0 \mu \mathrm{m}$. The regression coefficients have been estimated for classes of total column water vapor and satellite zenith angles. The emissivities are estimated as a weighted average of bare ground and vegetation elements within each pixel, with the fraction of vegetation cover directly generated from SEVIRI data [24]. The data are downloaded from http:/ /landsaf.ipma.pt. The SEVIRI LSTs have been evaluated by comparison with satellites products (MODIS) and with in situ measurements, with Root Mean Square (RMS) differences between $1 \mathrm{~K}$ and $2.5 \mathrm{~K}[18,25,26]$.

\subsection{The In Situ Measurements}

The ESA GlobTemperature Data User Element (DUE) project compiled in situ measurements from stations, over several major land cover types (http:www.globtemperature.info). For meaningful comparisons between the in situ and satellite retrieved temperature, stations were selected for their rather homogeneous land surfaces within the sensor field-of-views. The stations are listed in Table 1, grouped by climate types. Three of them (EVO, GBB, and KAL) are run by the Land Surface Analysis Satellite Applications Facility (LSA SAF) [13] and have narrowband infrared radiometers dedicated to the validation of MSG/SEVIRI LST. The LST is estimated from a simplified radiative transfer model with an uncertainty of $0.8 \pm 0.12 \mathrm{~K}$ [17]. The remaining seven (GCM, BND, PSU, SFA, FPK, DRA, and TBL) belong to the Surface Radiation Network (SURFRAD) [16] and use broadband infrared radiometers that are part of a suite of different instruments dedicated to measure long time series of radiation-related variables. The LST is computed via the Stephan-Boltzmann law using measured upwelling and downwelling radiances, with overall uncertainty of $0.6-2 \mathrm{~K}$.

Table 1. Characteristics of the in situ stations measuring the LST.

\begin{tabular}{llll}
\hline ID (Longitude, Latitude) & Location & Climate & Surface Type \\
\hline GCM $(-89.9,34.2)$ & Goodwin Creek, Mississippi, USA & Humid subtropical & Forest, grassland \\
PSU $(-77.9,40.7)$ & Pennsylvania State University, Pennsylvania, USA & Humid continental & Forest, cropland \\
BND $(-88.4,40.0)$ & Bondville, Illinois, USA & Humid continental & Cropland \\
SFA $(-96.6,43.7)$ & Sioux Falls, South Dakota, USA & Humid continental & Cropland, grassland \\
FPK $(-105.1,48.3)$ & Fort Peck, Montana, USA & Semiarid & Cropland, grassland \\
TBL $(-105.2,40.1)$ & Table Mountain, Boulder, Colorado, USA & Highland & Rocks, sparse grassland \\
DRA $(-116.02,36.62)$ & Desert Rock, Nevada, USA & Arid & Arid shrubland \\
EVO $(-8.00,38.5)$ & Evora, Portugal & Mediterranean & Savanna, woody savanna \\
GBB $(15.05,-23.55)$ & Gobabeb, Namibia & Arid & Bare ground \\
KAL $(18.3,-23.0)$ & Kalahari, Namibia & Arid & Shrubland \\
\hline
\end{tabular}

\subsection{Data Preparation for Comparisons}

In this study, the LSTs were compared for 2010, over the four seasons (January-February, April-May, July-August, and October-November), and from four different products (summarized in Table 2). Our purpose is to evaluate the LST of these products at continental, regional and local scales, and then to quantify their diurnal and seasonal discrepancies. These products have different spatial and temporal resolutions and need to be carefully collocated for comparisons. In addition, the infrared satellite observations are strongly affected by clouds. The data preparation is described 
as follows. Firstly, SEVIRI data were aggregated to the ISCCP pixel, and SEVIRI cloud flag was adopted for all comparisons involving this instrument. If ISCCP data were available at the same time, the ISCCP cloud flag was also applied, reducing the number of matchups but limiting the possible cloud contamination. Then clear-sky infrared data from ISCCP and SEVIRI were averaged to the ERA5 grid of $0.25^{\circ}$. Over a studied season, if the ERA5 grid had less than five days of valid data, the grid was not used. The snow-covered pixels were kept in all the products. These data were then used in the large-scale LST comparisons in the below.

Table 2. Characteristics of the Land Surface Temperature (LST) products from the ECMWF reanalyses and from the infrared satellites.

\begin{tabular}{lllll}
\hline Product & Spatial Coverage & Spatial Resolution & Temporal Resolution & References \\
\hline ECMWF ERA5 & global & $0.25^{\circ}$ & $1 \mathrm{~h}$ & {$[21]$} \\
ECMWF ERA Interim & global & $0.25^{\circ}$ & $6 \mathrm{~h}$ & {$[27]$} \\
ISCCP & global & $0.1^{\circ}$ & $3 \mathrm{~h}$ & {$[22]$} \\
SEVIRI & regional & $3 \mathrm{~km}$ & $15 \mathrm{~min}$ & {$[28]$} \\
\hline
\end{tabular}

\section{Large-Scale LST Comparisons}

In this section, we compare the LST from ERA5, ERA Interim, ISCCP, and SEVIRI, over the SEVIRI disk. The comparisons were made over the $0.25^{\circ}$ ERA grid. Figure 1 presents the differences ERA5-Interim, ERA5-ISCCP, and ERA5-SEVIRI at 00 and 12 UTC, averaged over months for two seasons (January-February and July-August). All data were available at 00 and 12 UTC, so these figures are representative of the general patterns of temperature differences without temporal interpolation. As expected, the two ECMWF products were close to each other, but some differences were nevertheless noted, especially over the inter-tropical zone during the day. During the daytime over arid and semi-arid regions, the infrared-derived ISCCP LST were clearly larger than the ERA5 LSTs (5 K or more on average), but the opposite prevailed over dense vegetation (in the order of $2-5 \mathrm{~K}$ ). SEVIRI also tended to provide larger LSTs than ERA5 over arid regions during the day, but the difference was smaller than with ISCCP.

Figure 2 presents the corresponding number of clear-sky collocations over the two time periods. Differences between the reanalysis and the infrared-derived satellite tended to increase when the number of collocations were reduced, during the cloudy seasons. For instance, the area of large discrepancies over the equator in Africa in January-February (Figure 1) corresponded to large cloud coverage (Figure 2), and it moved northward with the Intertropical Convergence Zone (ITCZ) during July-August. Such a seasonal cycle was also reported in previous studies [29-31]. Thus it is likely that cloud contamination still impacts the LSTs from infrared satellites, as well as the reanalyses, despite the stringent cloud clearing procedure. 

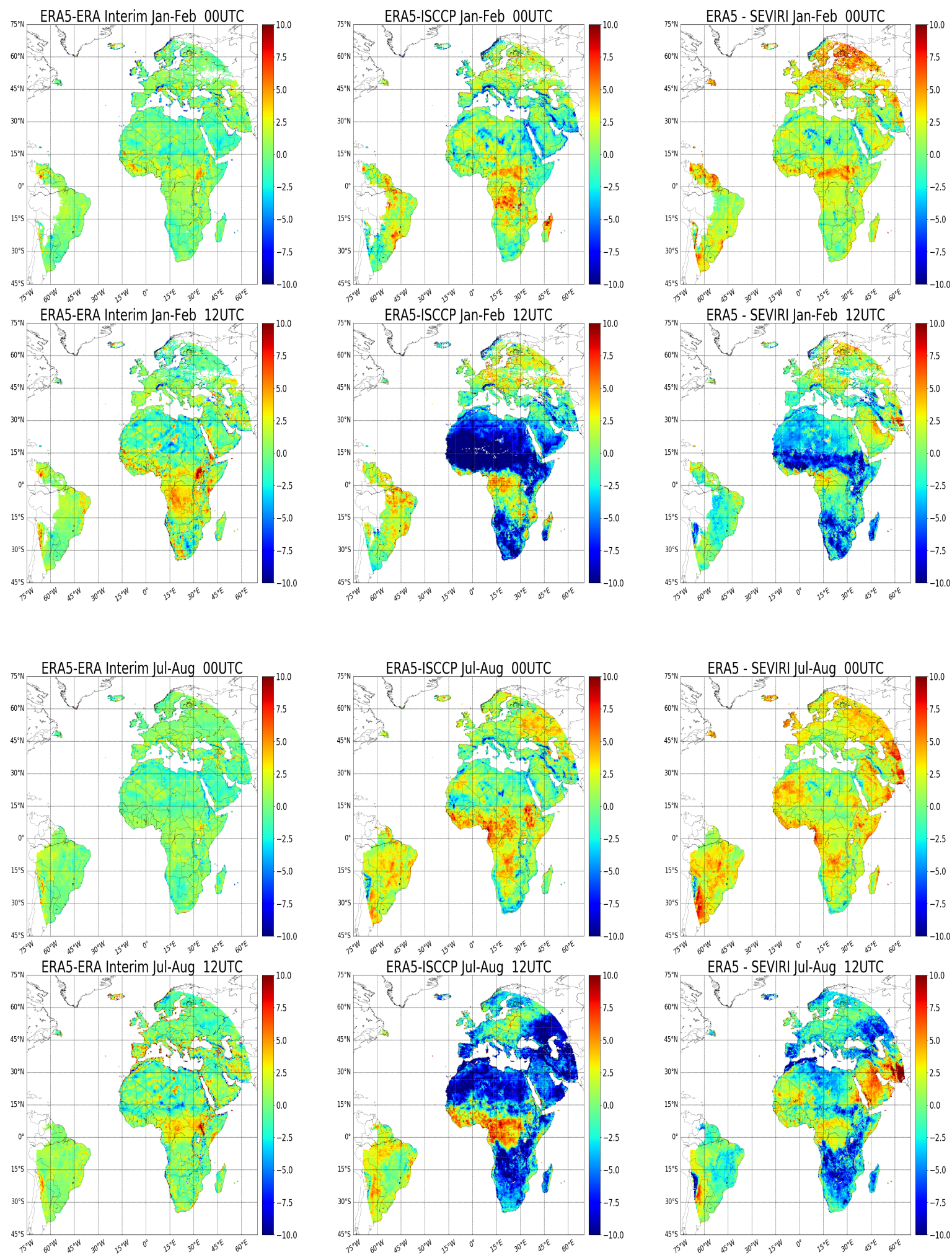

Figure 1. Monthly mean differences of LST (unit: K) for ERA5-ERA Interim, ERA5-ISCCP, and ERA5-SEVIRI at 00 UTC and 12 UTC of two seasons, i.e., January-February, July-August in 2010. The first two rows shows the results in January-February, with 00 UTC at top and then 12 UTC below. The last two rows show the results at the same UTCs in July-August. There are three columns, the left one shows ERA5-ERA Interim, the middle one ERA5-ISCCP, and the right one ERA5-SEVIRI. 

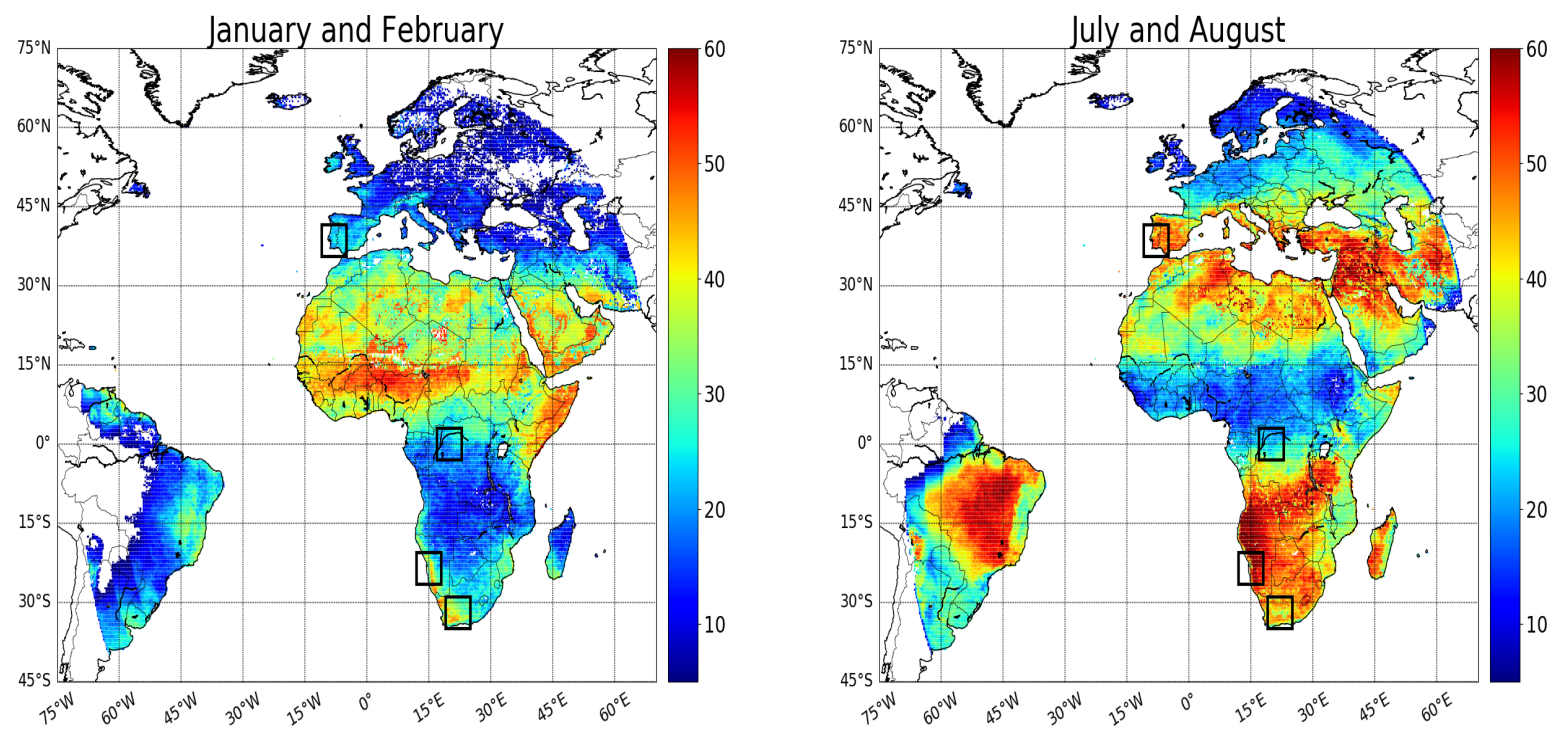

Figure 2. Number of clear-sky collocations between ISCCP and ERA5 for January-February (left) and July-August (right) 2010. From north to south, the selected regions are in: (1) Portugal, (2) Congo, (3) Namibia and (4) South Africa.

The resulting collocated data were now sorted by local times. We selected four regions under different environments (including two in situ stations). They are indicated in Figure 2: a rain forest location in Congo, the in situ Evora site in Portugal, shrubland in South Africa, and the in situ Gobabeb site in the Namibian desert. Each region had a size of $6^{\circ}$ (lat) $\times 6^{\circ}$ (lon). Figure 3 shows the diurnal mean temperature of the different products for these locations, as well as their difference with ERA5 (Figure 4), for the four seasons.

Regardless of the surface type, ERA Interim tended to produce a reduced amplitude of the diurnal cycle of LSTs, with lower LSTs at midday and slightly higher temperature during the night. This is partly due to the $6 \mathrm{~h}$ sampling of this product that can miss the maximum and minimum LSTs at local time. The diurnal cycle over dense vegetation (here rain forest) was limited, as expected. ERA5 produced larger LSTs than the other products in this region (including ERA Interim); for example it was about $2 \mathrm{~K}$ more than SEVIRI and 2-4 K than ISCCP. Balsamo and Betts [21,32] reported that both TESSEL (used in ERA Interim) and HTESSEL (ERA5) underestimated rainfall and reduced run off in tropical forest significantly. This rainfall underestimation in addition to other issues such as radiation and cloud could lead to higher surface temperature in the reanalyses.

Over the other surface types, strong diurnal cycles and seasonal variations were observed in the LSTs, with rather limited differences between the products at night. More discrepancies between the reanalyses and the infrared estimates could be found in the day, with a maximum close to the maximum LSTs (shortly after midday local time), and the reanalyses underestimating the maximum LSTs. ISCCP produced significantly larger LSTs during the day than the other estimates, especially under arid and semi-arid environments. This has already been observed in the previous versions of the ISCCP products [33]. 


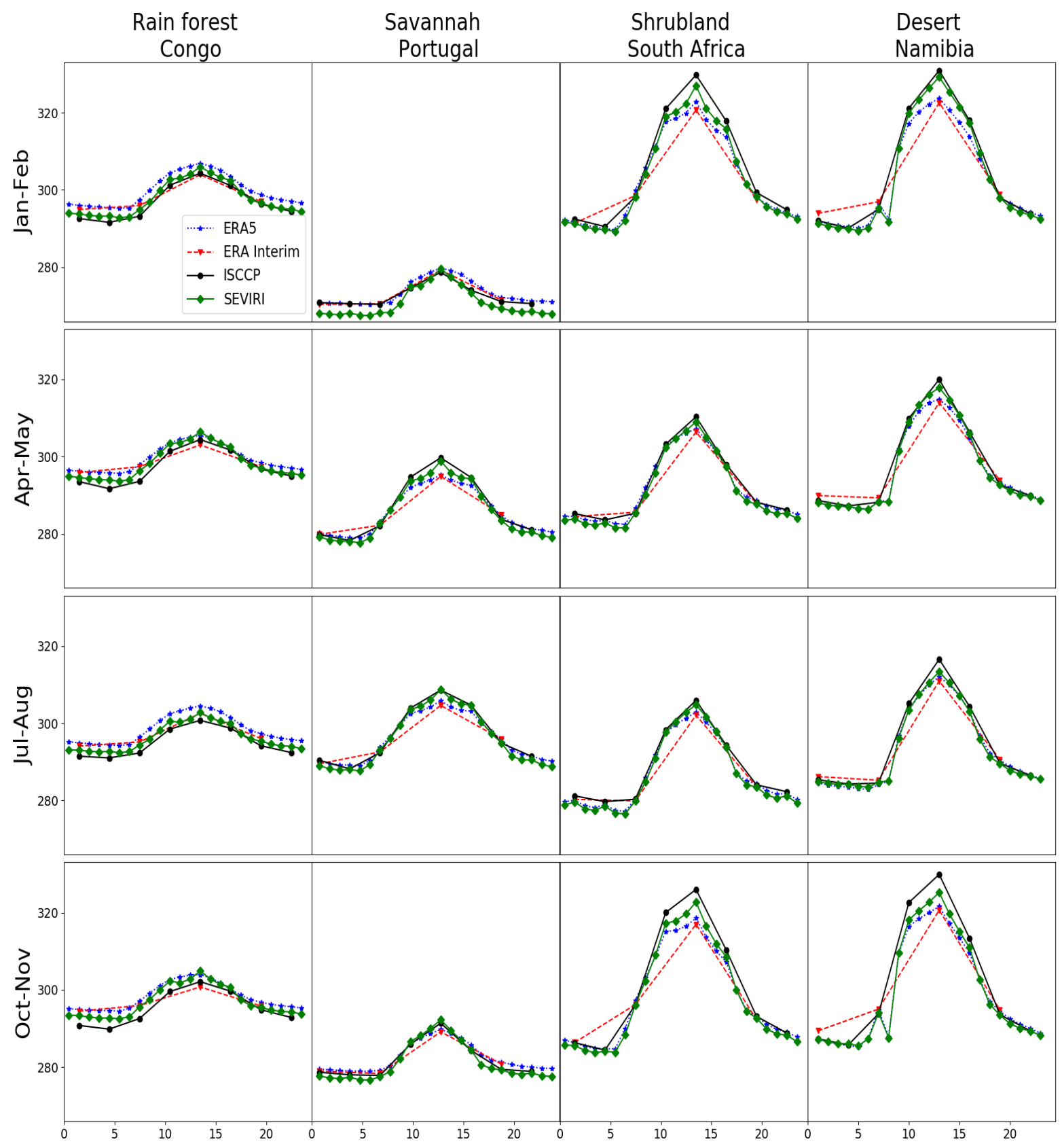

Figure 3. Diurnal LST variations (unit: K) for ERA5, ERA Interim, ISCCP, and SEVIRI over four selected vegetation types in January-February, April-May, July-August, and October-November in 2010. $X$-axis represents local time. The columns represent four selected regions, and the rows for the four seasons. 


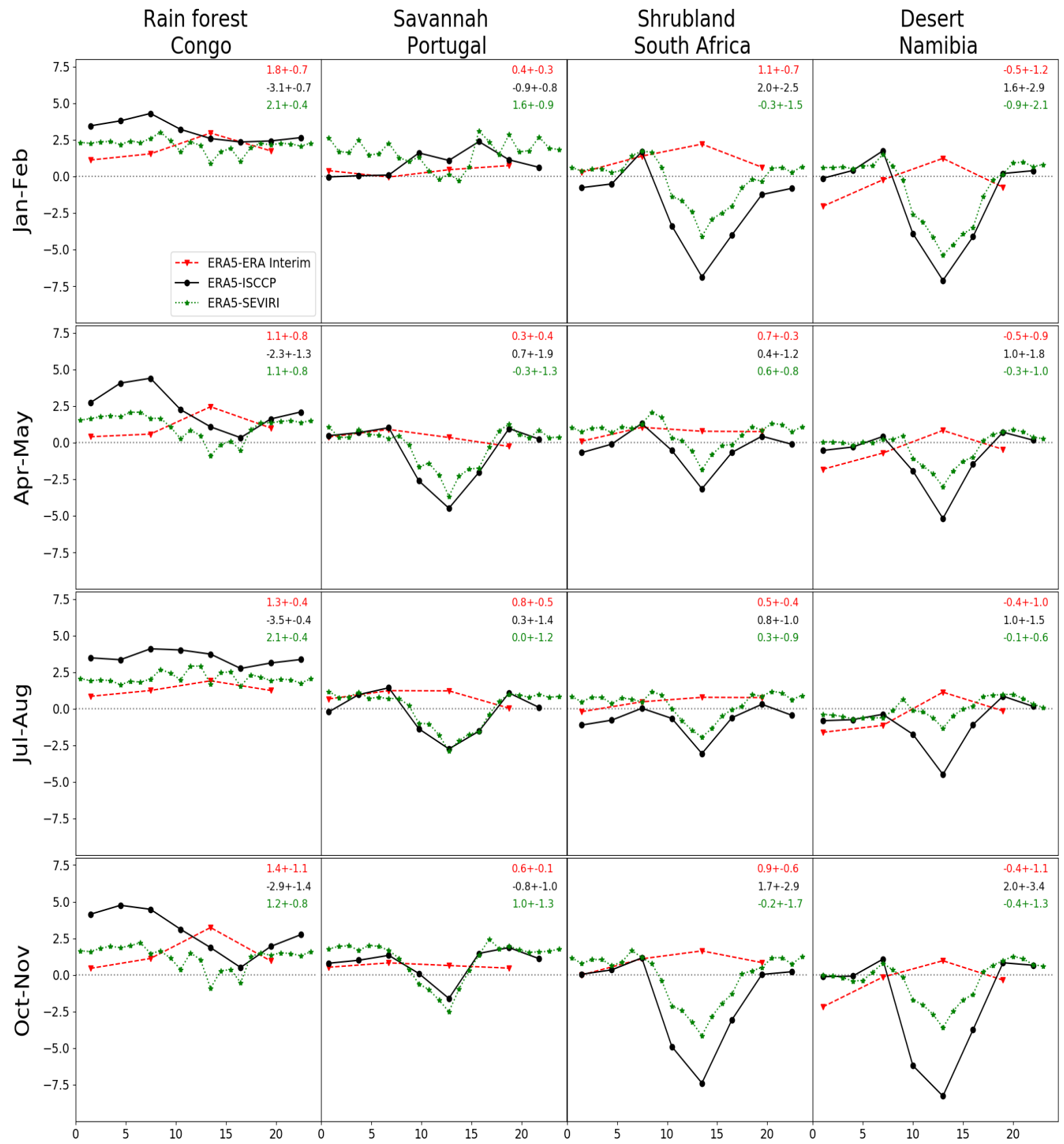

Figure 4. Diurnal LST bias variations (unit: K) for ERA5-ERA Interim, ERA5-ISCCP, ERA5-SEVIRI over four selected vegetation types in January-February, April-May, July-August, and October-November in 2010. $X$-axis represents local time. The columns represent four selected regions, and the rows for the four seasons.

\section{Comparisons with In Situ Observations}

In this section we use the in situ measurements to evaluate LST products. The in situ observations had high temporal (every $1 \mathrm{~min}$ ) resolution. Their spatial representiveness was within $100 \mathrm{~m} \times 100 \mathrm{~m}$ (maybe more if the surface homogeneity was high) [17,34]. For meaningful comparisons, stations were selected for their rather homogeneous land surfaces. The closest in space ECMWF reanalyses, ISCCP, and SEVIRI pixels were selected for the comparisons. The locations of all the stations and the corresponding satellite pixels (if available) are displayed in Figure 5. Concerning the surface around stations, the land cover near SFA, TBL and BND were reported to have concerns of heterogeneity, according to $[35,36]$. 


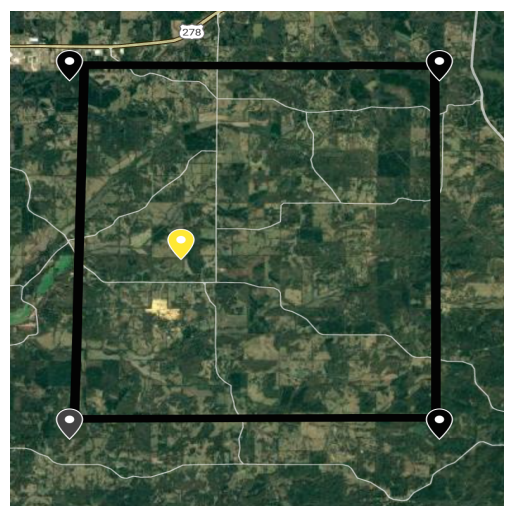

(a) GCM, Mississippi

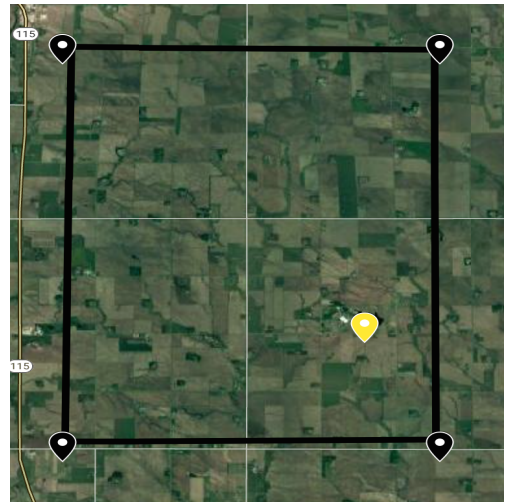

(d) SFA, South Dakota

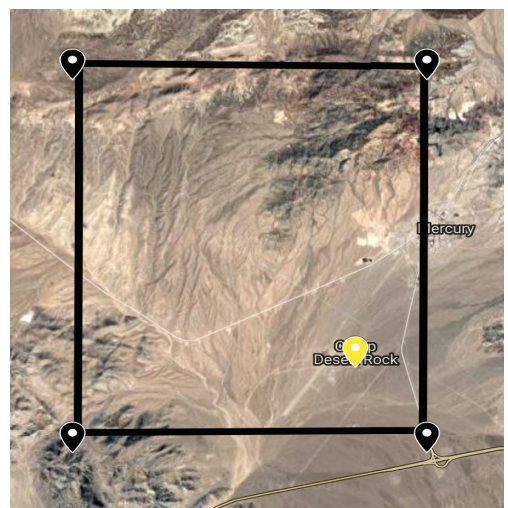

(g) DRA, Nevada

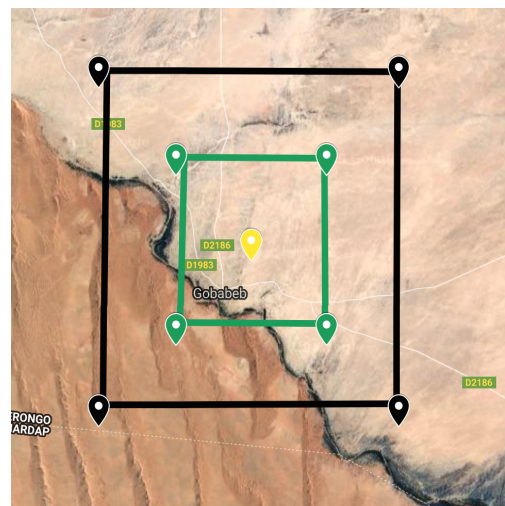

(j) GBB, Namibia

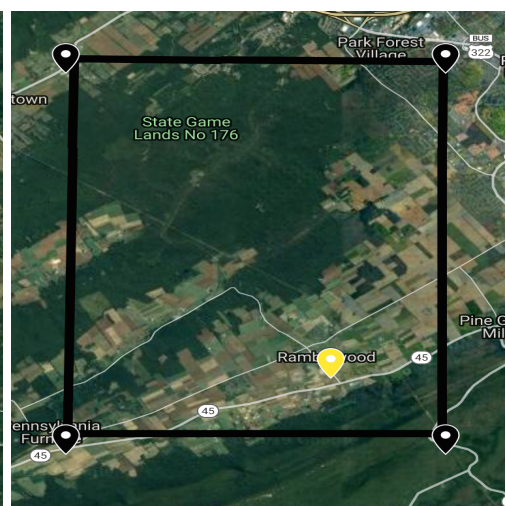

(b) PSU, Pennsyvania

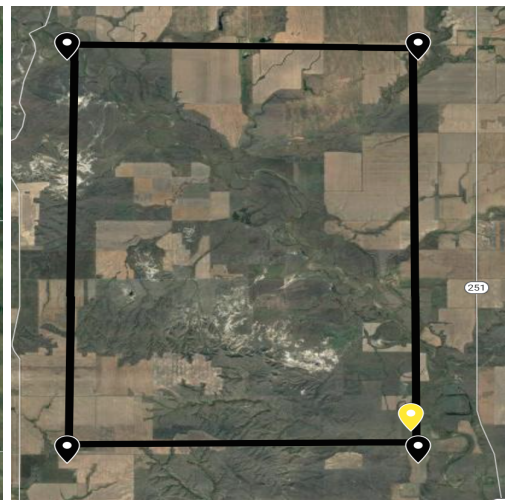

(e) FPK, Montana

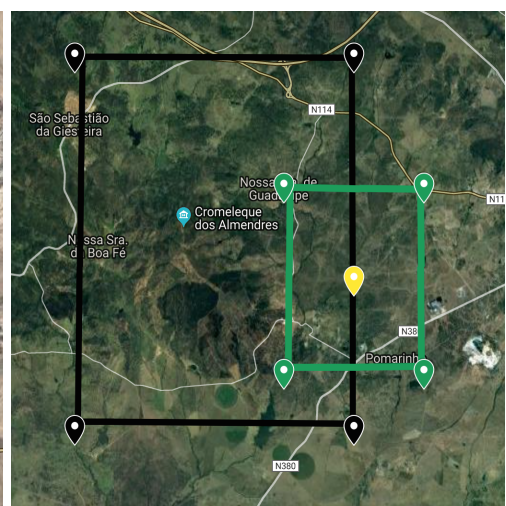

(h) EVO, Portugal

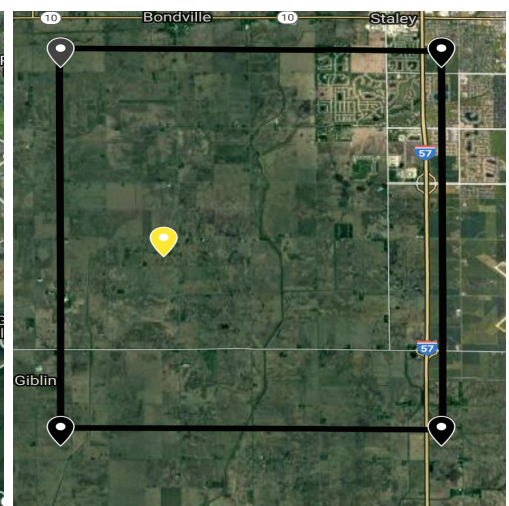

(c) BND, Illinois

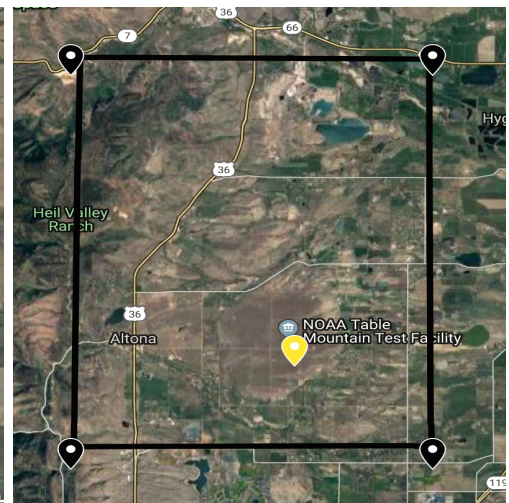

(f) TBL, Colorado

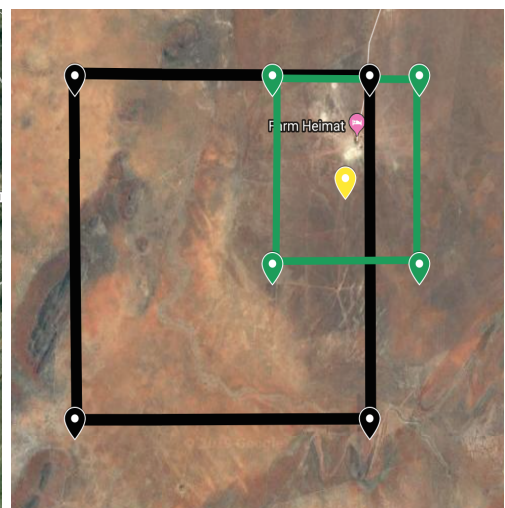

(i) KAL, Namibia

Figure 5. The locations of the ground stations and corresponding satellite pixel when available. Black: ISCCP pixel. Green: SEVIRI. Yellow: ground station. The satellite image is from Google map. 
Emissivity assumptions from the in situ measurements and the satellite processing were different. GBB in situ station used a constant emissivity $0.94 \pm 0.015$, while the other KIT stations made use of the operational emissivity product from LSA SAF. At the SURFRAD stations, the Cooperative Institute for Meteorological Satellite Studies (CIMSS) provides the emissivity database at $0.05^{\circ} \times 0.05^{\circ}$ [37], used to compute the monthly broadband emissivities. Figure 6 shows the mean emissivities calculated from LSA SAF for SEVIRI (originally estimated on a daily basis), for ISCCP (prescribed values according to surface types) and CIMSS (monthly mean). The emissivities showed different behaviors in their values and in their seasonal patterns.
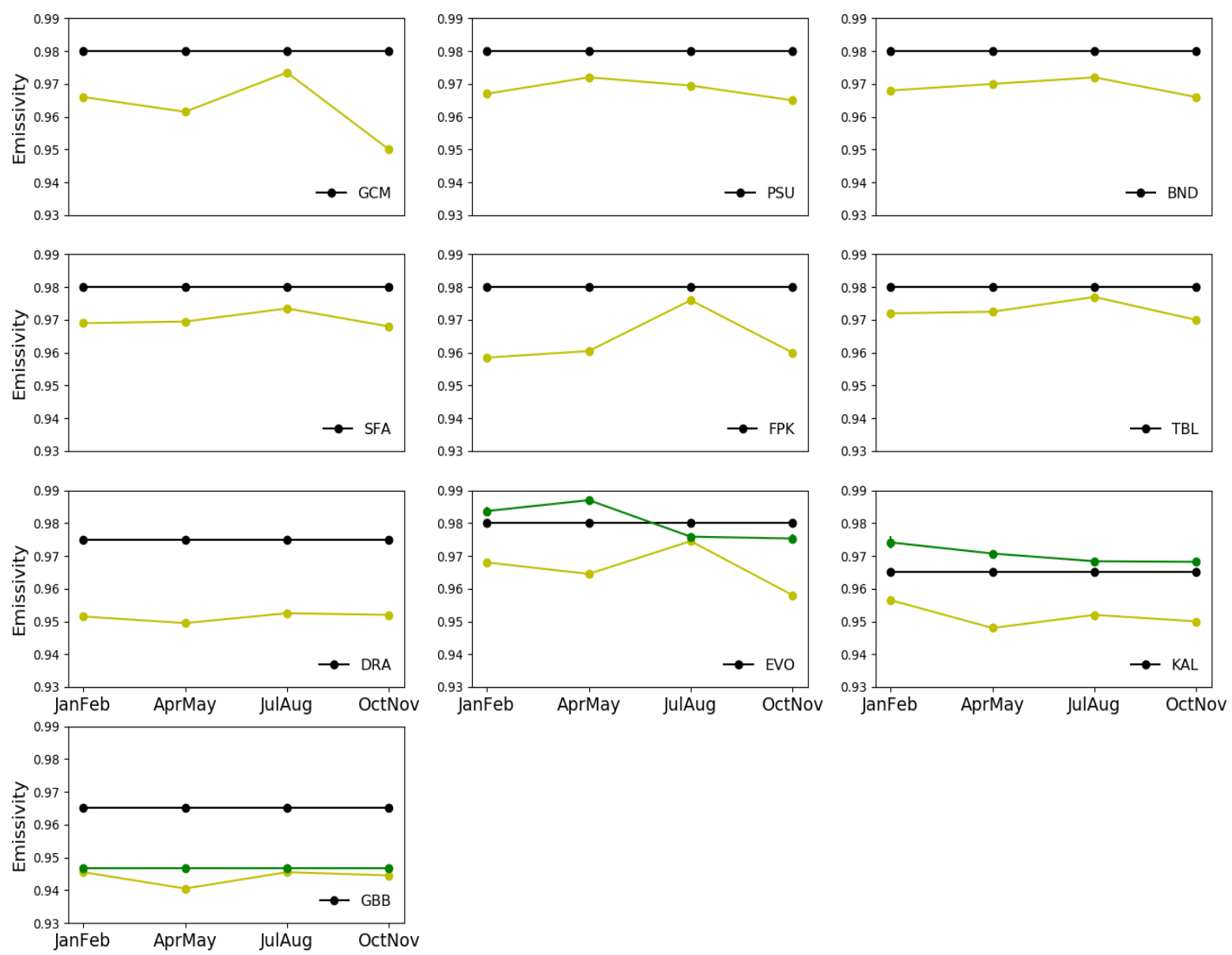

Figure 6. Emissivities used at the ground station location in the LST retrieval from ISCCP and SEVIRI (when available), and from the estimates of CIMSS. Black: ISCCP. Green: SEVIRI. Yellow: CIMSS.

Figure 7 presents the diurnal LST cycles during three selected days at KIT stations for example. Around midday, the in situ measurements could have rapid variations: they are likely related to some clouds that shadow the incoming sun radiation. Figure 8 shows the mean diurnal variations of LST, averaged over two month periods under clear sky conditions. Good general agreement was observed among the products in this figure, with similar spatial, seasonal, and diurnal patterns. Some exceptions were observed in winter, for likely snow covered surfaces at BND, PSU and SFA, where ISCCP was systematically colder compared to the reanalyses and the in situ data when the temperature was below or close to $0{ }^{\circ} \mathrm{C}$. ISCCP used a fixed emissivity of 0.99 for pixels that were identified as snow, but the large temporal and spatial variations of snow within ISCCP pixels may have existed, resulting in emissivity inaccuracies. Temperature retrieval could also be complex due to more difficulties in cloud identification over snow-covered surfaces, as noted by [11]. In arid and semi-arid regions, ISCCP tended to overestimate the LST at midday, as compared to the in situ measurements. The other products did not show such systematic disagreements with the in situ measurements. 

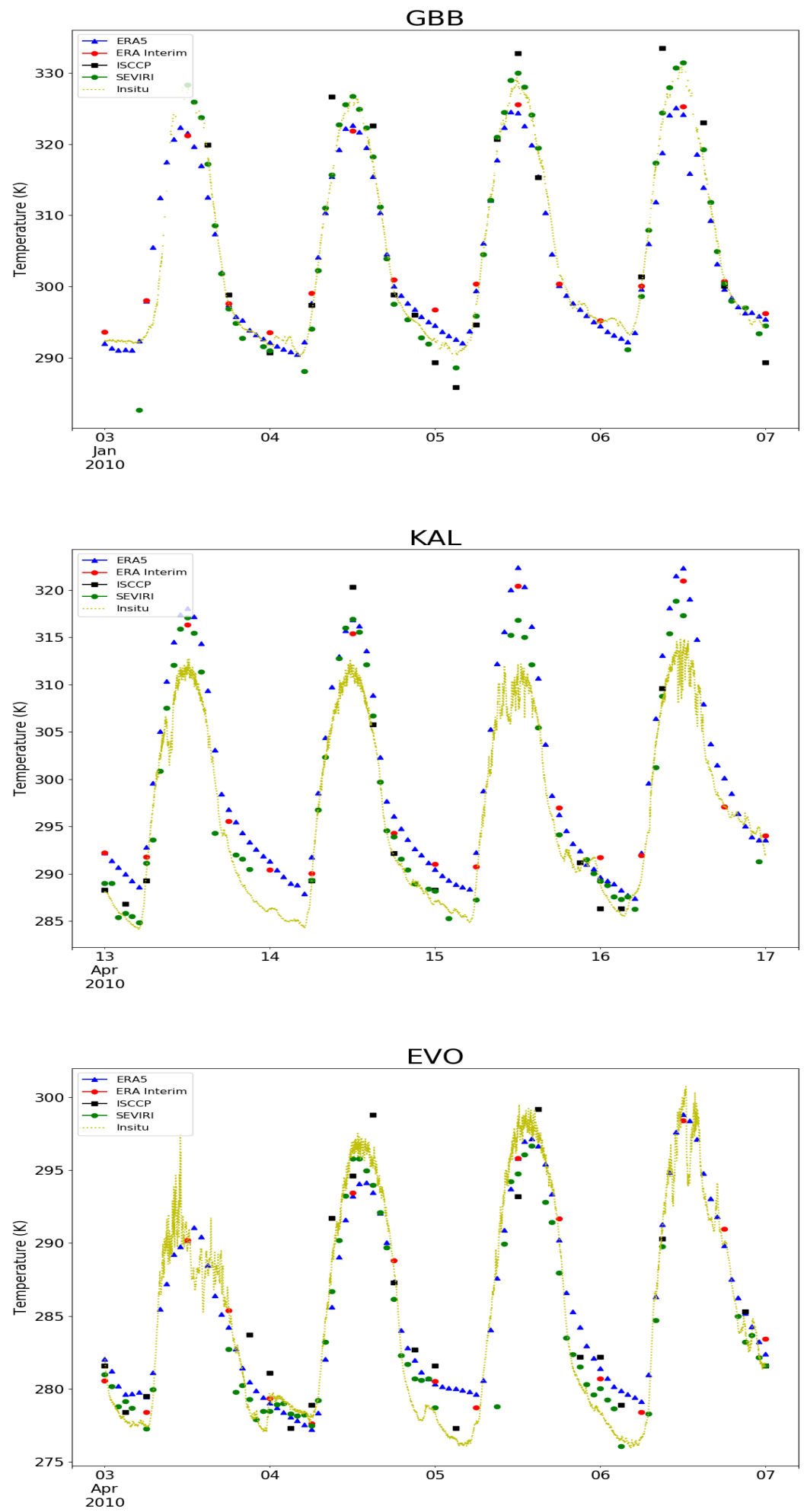

Figure 7. Example observations at GBB, KAL and EVO from ERA5, ERA Interim, ISCCP, SEVIRI, and in situ respectively in 2010. 


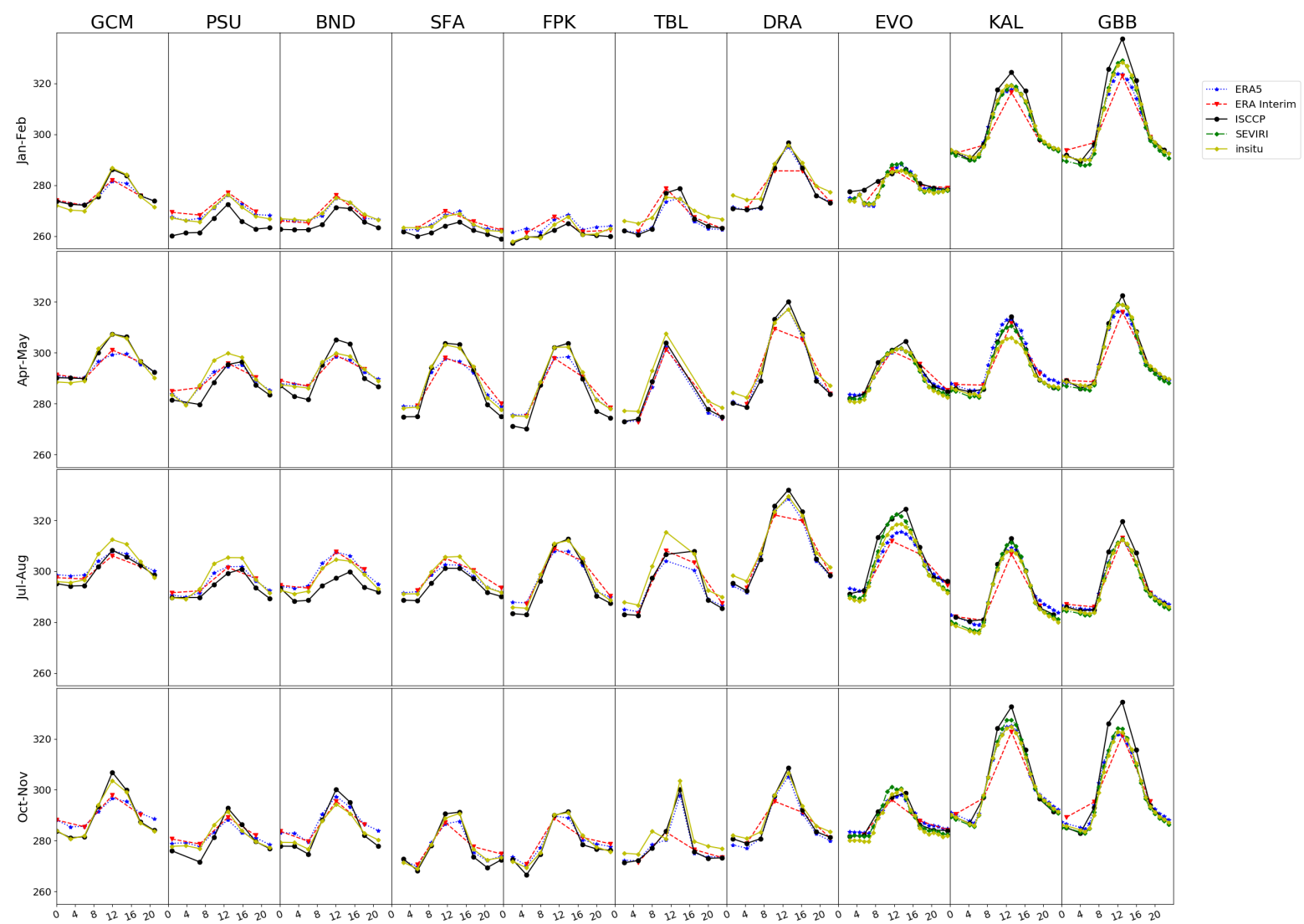

Figure 8. Diurnal variations of monthly mean LST (unit: K) over selected stations, from ERA5, ERA Interim, ISCCP and SEVIRI (when available), and in situ measurements. X-axis represents local time.

The mean differences between the in situ measurements and satellite/reanalysis products are shown in Figure 9. The results of the KIT and the GCM stations are studied with more details below. Brief information is provided with station environment and climate, and more information can be found in $[16,17,38]$.

\section{GBB: Arid station in Namibia}

The station is covered by highly homogeneous mixture of gravel, sand and sparse desiccated grass. A sharp transition between sand dunes and the gravel plains is shown in Figure 5. SEVIRI pixels are on the gravel plains only, while ISCCP pixel covers both gravel and sand dunes. It has a hot and arid climate, with the rainy season in January-March.

SEVIRI exhibited excellent agreement with the in situ, especially during the cool seasons (April-May and July-August), with absolute bias less than $1 \mathrm{~K}$. During the hot and rainy season (January-February), SEVIRI night temperature was about $2 \mathrm{~K}$ lower than the in situ LST, likely due to cloud contamination in the satellite retrieval as mentioned in [18]. During daytime in October-November, SEVIRI LST tended to be overestimated compared to the in situ (though less than ISCCP), and this is partially due to emissivity errors under arid conditions [18]. ISCCP agreed well with the in situ measurements at night, but it overestimated LST around midday by more than $5 \mathrm{~K}$ on average.

Concerning the two ECMWF reanalyses, ERA Interim could overestimate nighttime temperatures by about $4 \mathrm{~K}$ while ERA 5 often had absolute bias less than $1 \mathrm{~K}$. Smaller bias of ERA5 can be attributed to the new diffusivity and conductivity model of HTESSEL, as the new model can reduce the overestimation of soil moisture in barren soil [21,39]. 


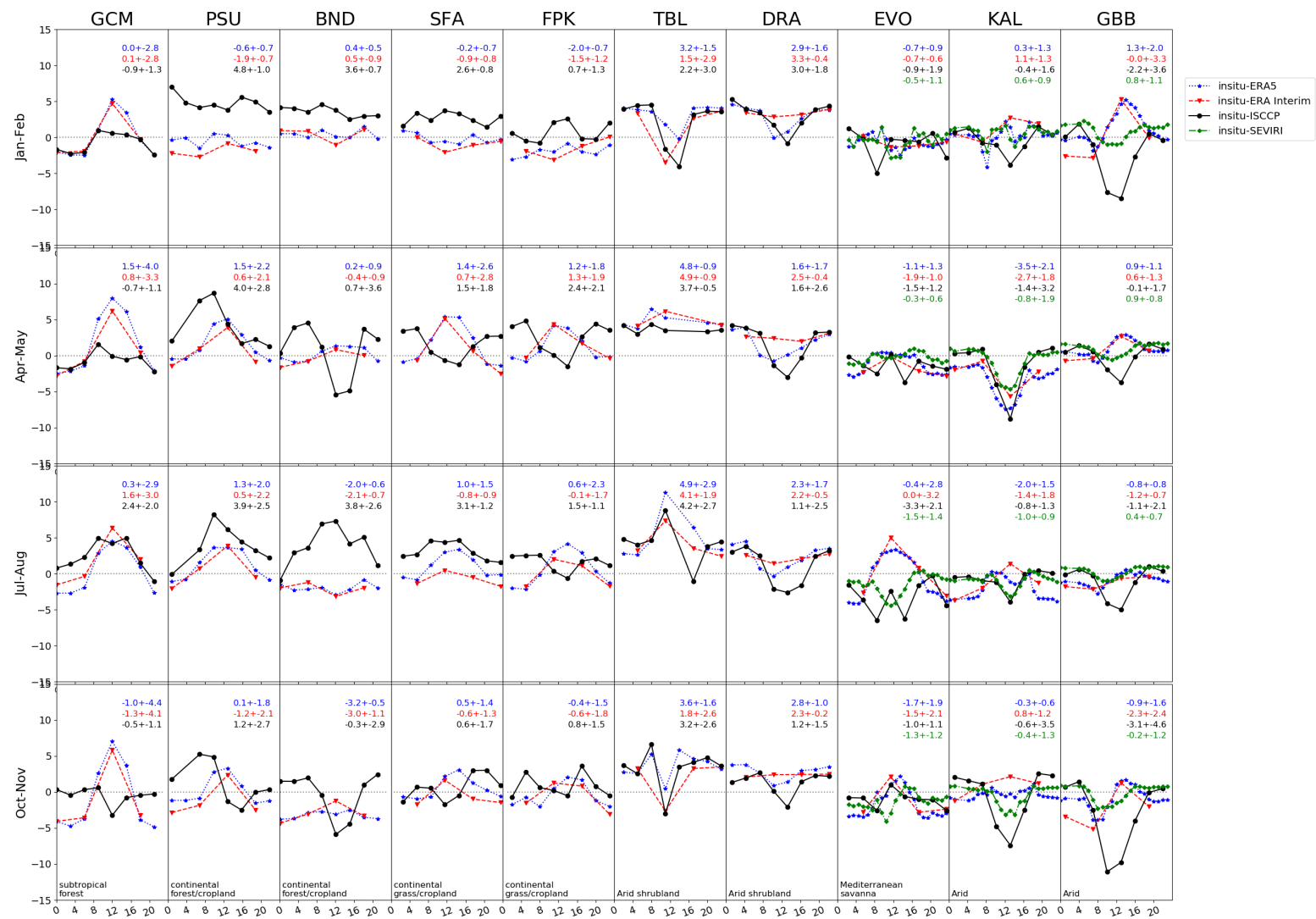

Figure 9. Diurnal variations of monthly mean differences of LST (unit: K) at selected stations, i.e., In situ-ERA5, In situ-ERA Interim, In situ-ISCCP and In situ-SEVIRI (when available). X-axis represents local time.

\section{KAL: shrubland station in Namibia}

This station is located in a farm and the surface is a mixture of grass and sand. When more rain comes in January-March, grass is abundant; but in other seasons grass may dry out quickly as reported by [19]. ISCCP covers more sandy areas than SEVIRI (Figure 5).

Though remote sensed LST shows good coherence with the in situ at night, SEVIRI and ISCCP tended to overestimate temperature near midday. The overestimation was much less during the rainy season when grass is abundant. Concerning the two ECMWF reanalysis, they fit quite well the in situ LST during the rainy seasons (January-February), while some overestimation appeared in drier seasons, often at night. Compared to GBB, the error sources here may have been more complex due to surface vegetation variations in space and time.

\section{EVO: Mediterranean woody savanna}

This station is located in woodland plains in Portugal. The climate is characterized by hot and dry summer and cold and rainy winter. The in situ temperature is a weighted average from three infrared radiometers, observing the sunlit background, a tree crown and the sky at $53^{\circ}$ zenith angle $[17,18,25]$. The emissivity is the same of station and of LSA SFA retrieval. ISCCP may cover more dense forest than SEVIRI (Figure 5).

SEVIRI had the best diurnal agreement in rather cold seasons, i.e., January-February and April-May, with absolute bias less than $1 \mathrm{~K}$. More differences appeared in summer daytime, with remote-sensed temperature higher than the in situ. This can be partially due to high variabilities of temperature and emissivity between tree canopies and the ground in warm seasons, which may have resulted in larger uncertainty in the in situ observations, as also mentioned in previous studies $[13,25,26]$. 
The two reanalyses tended to overestimate LST at night and underestimate it in the summer daytime, which is consistent with previous results [40]. Johannsens [40] evaluated the impacts of vegetation parameters on ECMWF LSTs over the Iberian Penisula, by using GLCC (Global Land Cover Characterization which was also used in the reanalyses) and several other land-cover datasets. They found that the inaccuracies of vegetation cover used in the reanalyses could explain part of the discrepancy between the reanalyses and SEVIRI.

\section{GCM: subtropical station in the US}

It is located in subtropical forest mixed with cropland, and the surface is rather homogeneous [36]. The two ECMWF reanalyses show higher/lower temperature in night/day than in situ measurements for all seasons. In the work of [39], modelled soil moisture were compared to in situ observations provided by the NRCS-SCAN (Natural Resources Conservation Service Soil Climate Analysis) Network in the United States. They found that HTESSEL estimates more soil moisture than the ground measurements, especially over vegetated surface such as forest, grass and cropland (which happens to TESSEL as well). Thus the overestimation of soil moisture may be an important reasons to the diurnal LST differences compared to the in situ. The land cover and vertical soil discretization used in the reanalyses may also play a relevant role [40].

For the two reanalyses, over(under)estimation at night(day) were observed in transitional areas such as grassland, cropland, and forest, for example at stations of GCM, FPK, PSU, etc. In these zones, a strong coupling existed between soil moisture and atmosphere which could influence temperature [41,42]. In the reanalyses, soil moisture, aerodynamic (Zom) and thermal (Zoh) roughness length were directly linked to evaporation, hence to the LST. The two roughness lengths had fixed values at a given surface type, and this could result in some errors compared to observations $[28,40,43]$. Previous studies have shown that these two roughness lengths vary with vegetation and may have seasonal cycle [44,45].

The diurnal variations of roughness lengths were recently studied in several regions using field observations and modelling [46-48]. For example [47] found the diurnal variations of Zom with larger Zom at night and smaller during the day in mid-latitude forest. Pitman [49] pointed out that 30\% of Zom error could result in 15\% uncertainty in fluxes calculations. Underestimation of Zom (if at night) means less surface-atmosphere coupling, thus higher surface temperature [28]; overestimation (if in the day) means more surface-atmosphere interactions and lower LSTs. Zhang [46] found also that high/low Zoh could over/underestimate sensible and latent heat flux, leading to lower/higher surface temperature. Thus, the adjustment of roughness length values with temporal variations may be useful to improve the model surface processes and their interactions with atmosphere, hence the LST estimation.

Figure 10 summarizes the statistics over 2010, i.e., correlation with the in situ measured LST, mean and root-mean-square (RMS) of differences compared to the in situ data. All the products had good correlations of more than 0.95 , which is related to the diurnal cycle representation (except less correlations of ISCCP at some stations). SEVIRI has smaller RMS and larger correlation than the other three products, that is, better agreement to the in situ measurements, knowing that their retrievals had been validated at the KIT stations. ISCCP had higher RMS and less correlations in almost all the stations, particularly on snow influenced surface, that is, PSU, BND, SFA, and FPK. 

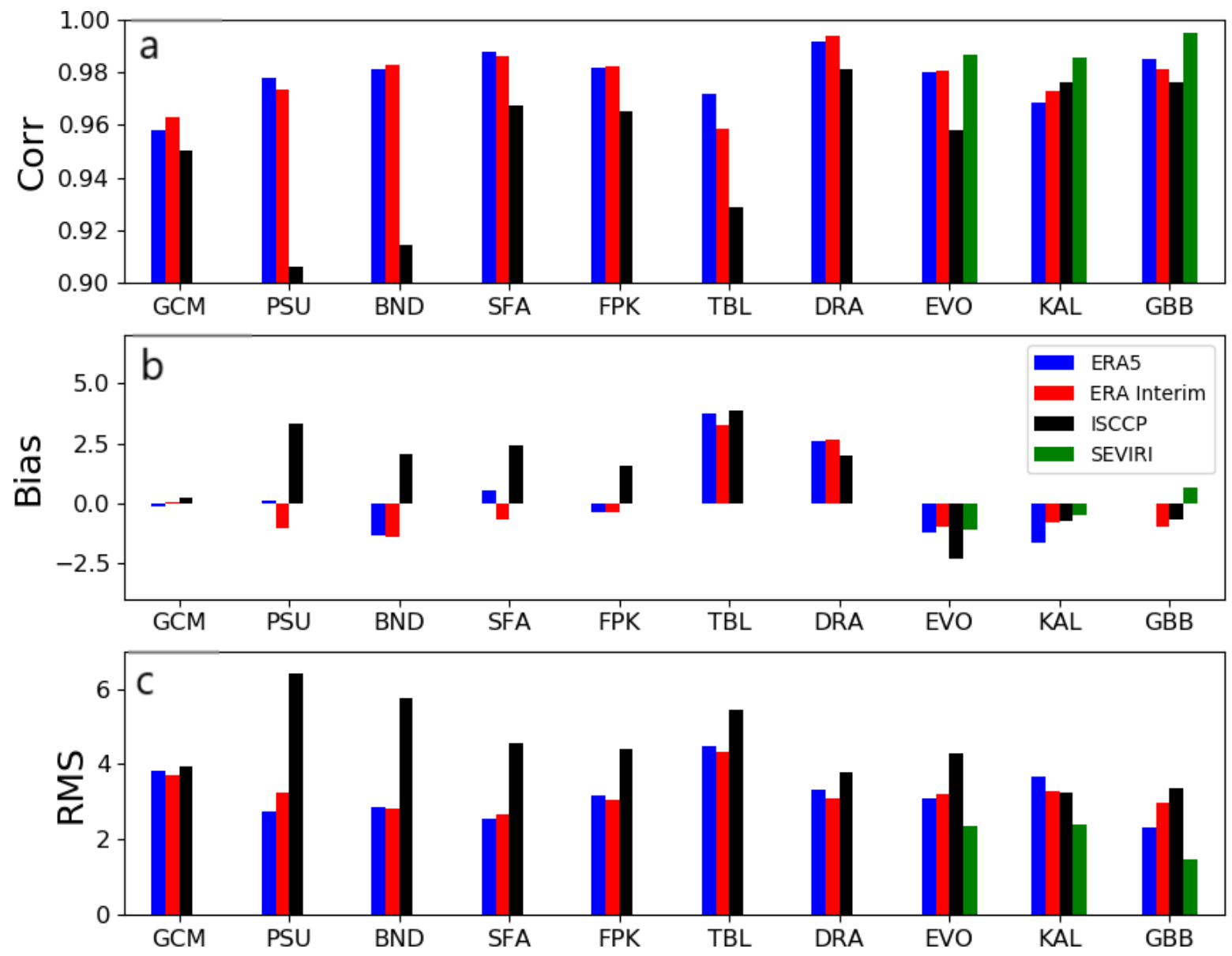

Figure 10. (a) Correlation of LST products to the in situ measurements at each station over all the seasons. (b) Mean of the differences (Unit: K) in comparison to the in situ measurements at each station over all the seasons. (c) Root-mean-square (RMS) of the differences (Unit: K) in comparison to the in situ measurements at each station over all the seasons.

\section{Conclusions}

This study analyzed the diurnal variations of LST estimates from ECMWF reanalyses (ERA5 and ERA Interim), from infrared satellite instruments (ISCCP, SEVIRI), and from in situ measurements. Clear-sky data from four seasons in 2010 were analyzed. Firstly we compared satellite and reanalysis data within the SEVIRI disk. Then, the comparison focused on in situ measurements at 10 dedicated ground stations.

Spatial, seasonal and diurnal variations of LST are compared. In general more differences are seen in warm seasons than cold ones, more at midday than at night. At the three KIT stations, SEVIRI shows better agreement with the in situ measurements than the other products (in bias, correlation, and RMS differences), with bias often less than $\pm 2 \mathrm{~K}$ and correlation of 0.99 . Over snow or arid surface ISCCP seems to have more systematical errors than the other products (no SEVIRI data are available over snow-influenced stations). The validation of satellite retrievals can be still influenced by cloud contamination, surface heterogeneity, and emissivity inaccuracies, despite the stringent cloud clearing and collocation procedures.

The differences between the ECMWF reanalyses and LST observations vary with land cover. Over barren land, ERA5 shows better agreement to the in situ than ERA Interim, particularly at night time (with the discrepancy reduced by $\sim 3 \mathrm{~K}$ in maximum), thanks to the new surface model. Over vegetated surface, both models tend to have higher/lower temperature at night/day time than the in situ measurements. This may be linked to the overestimation of soil moisture and the limitations in surface-atmosphere coupling in the models. 
Author Contributions: Conceptualization, X.W. and C.P.; software, analysis, visualization, writing the original draft, X.W.; writing-review and editing, C.P. All authors have read and agreed to the published version of the manuscript.

Acknowledgments: We are thankful to the EUMESAT Land SAF for providing the SEVIRI LST observations, to the NOAA National Center for Environmental Information (NCEI) for the ISCCP estimates, and to ECMWF and the Copernicus Climate Data Store for the ECMWF ERA reanalyses. The in situ observations were kindly provided by the ESA GlobTemperature Data User Element project. We are grateful to Carlos Jimenez for constructive discussions during this study.

Conflicts of Interest: The authors declare no conflict of interest.

\section{References}

1. Pongracz, R.; Bartholy, J.; Dezso, Z. Remotely sensed thermal information applied to urban climate analysis. Adv. Space Res. 2006, 37. doi:10.1016/j.asr.2005.06.069

2. Hung, T.; Uchihama, D.; Ochi, S.; Yasuoka, Y. Assessment with satellite data of the urban heat island effects in Asian mega cities. Int. J. Appl. Earth Obs. Geoinf. 2006, 8, 34-48. doi:10.1016/j.jag.2005.05.003

3. Sobrino, J.A.; Raissouni, N. Toward remote sensing methods for land cover dynamic monitoring: Application to Morocco. Int. J. Remote Sens. 2000, 21, 353-366. doi:10.1080/014311600210876.

4. Anderson, M.; Allen, R.G.; Morse, A.; Kustas, W.P. Use of Landsat thermal imagery in monitoring evapotranspiration and managing water resources. Remote Sen. Environ. 2012, 122, 50-65. doi:10.3390/rs11111334.

5. Kustas, W.; Anderson, M. Advances in thermal infrared remote sensing for land surface modeling. Agric. For. Meteorol. 2008, 149, 2071-2081. doi:10.1016/j.agrformet.2009.05.016.

6. Sun, D.; Pinker, R.T.; Kfatos, M. Diurnal Temperature Range Over the United States: A Satellite View. Geophys. Res. Lett. 2006, 33. doi:10.1029/2005GL024780.

7. Zhang, H.; Zhang, F.; Che, T.; Zhang, G. Estimating daily air temperatures over the Tibetan Plateau by dynamically integrating MODIS LST data. J. Geophys. Res. 2016, 121. doi:10.1002/2016JD025154.

8. Simon, M.; Plummer, S.; Fierens, F.; Hoelzemann, J.J.; Arino, O. Burnt area detection at global scale using ATSR-2: The GLOBSCAR products and their qualification. J. Geophys. Res. 2004, 109. doi:10.1029/2003JD003622.

9. Barbosa, P.M.; Gregoire, J.M.; Pereira, J.M.C. An algorithm for extracting burned areas from time series of AVHRR GAC data applied at a continental scale. Remote Sens. Environ. 1999, 69. doi:10.1029/2003JD003622.

10. Karnieli, A.; Agam, N.; Pinker, R.T.; Anderson, M. Use of NDVI and Land Surface Temperature for Drought Assessment: Merits and Limitations. J. Clim. 1999, 23. doi:10.1175/2009JCLI2900.1.

11. Rossow, W.; Schiffer, R. Advances in understanding clouds from ISCCP. Bull. Am. Meteorol. Soc. 1999, 80. doi:10.1029/2011JD017058.

12. Young, A.H.; Knapp, K.R.; Inamdar, A.; Hankins, W.; Rossow, W.B. The International Satellite Cloud Climatology Project H-Series climate data record product. Earth Syst. Sci. Data 2018, 10. doi:10.5194/essd-10-583-2018.

13. Trigo, I.F.; Boussetta, S.; Viterbo, P.; Balsamo, G.; Beljaars, A.; Sandu, I. The satellite application facility for land surface analysis. Int. Remote Sens. 2011, 32. doi:10.1080/01431161003743199.

14. Dee, D.P.; Uppala, S.M.; Simmons, A.J.; Berrisford, P.; Poli, P.; Kobayashi, S.; Andrae, U.; Balmaseda, M.A.; Balsamo, G.; Bauer, D.P.; et al. The ERA-Interim reanalysis: configuration and performance of the data assimilation system. Q. J. R. Meteorol. 2011, 137. doi:10.1002/qj.828.

15. (C3S). ERA5: Fifth Generation of ECMWF Atmospheric Reanalyses of the Global Climate. Copernicus Climate Change Service Climate Data Store (CDS). 2017. Available online: https: / cds.climate.copernicus. eu/cdsapp\#!/home (accessed on 10 February 2020).

16. Augustine, J.A.; Hodges, G.B.; Cornwall, C.R. An update on SURFRAD-The GCOS surface radiation budget network for the continental United States. J. Atmos. Oceanic Technol. 2005, 22. doi:10.1109/TGRS.2009.2027697.

17. Gottsche, F.M.; Olesen, F.S.; Bork-Unkelbach, A. Validation of land surface temperature derived from MSG/SEVIRI with in situ measurements at Gobabeb, Namibia. Int. J. Remote Sens. $2013,47$. doi:10.1080/01431161.2012.716539. 
18. Trigo, I.F.; Monteiro, I.T.; Olesen, F.; Kabsch, E. An assessment of remotely sensed land surface temperature. J. Geophy. Res. 2008, 113. doi:10.1029/2008JD010035.

19. Gottsche, F.M.; Olesen, F.S.; Trigo, I.F.; Bork-Unkelbach, A.; Martin, M.A. Long Term Validation of Land Surface Temperature Retrieved from MSG/SEVIRI with Continuous in-Situ Measurements in Africa. Int. J. Remote Sens. 2016, 8. doi:10.3390/rs8050410.

20. Jiménez, C.; Prigent, C.; Ermida, S.; Moncet, J. Inversion of AMSR-E observations for land surface temperature estimation: 1. Methodology and evaluation with station temperature. J. Geophys. Res. 2016, 122. doi:10.1002/2016JD026144.

21. Balsamo, G.; Viterbo, P.; Beljaars, A.; Hurk, B.V.D.; Hirschi, M.; Betts, A.K.; Scipal, K. A Revised Hydrology for the ECMWF Model: Verification from Field Site to Terrestrial Water Storage and Impact in the Integrated Forecast System. Am. Meteorol. Soc. 2009, 22. doi:10.1175/2008JHM1068.1.

22. Rossow, W.B. Climate Data Record Program (CDRP): Climate Algorithm Theoretical Basis Document (C-ATBD) International Satellite Cloud Climatology Project (ISCCP) H-Series; Technical Report; CDRP- ATBD-0872; CDRP: Asheville, NC, USA, 2017.

23. Wan, Z.; Dozier, J. A generalized split-window algorithm for retrieving land surface temperature from space. IEEE Trans. Geosci. Remote Sens. 1996, 34. doi:10.1109/JSTARS.2015.2441096.

24. Trigo, I.F.; Peres, L.; DaCamara, C.C.; Freitas, S.C. Thermal land surface emissivity retrieved from SEVIRI/Meteosat. IEEE Trans. Geos. Remote Sen. 2008, 46. doi:10.5194/essd-10-583-2018.

25. Ermida, S.; Trigo, I.; DaCamara, C.C.; Gottsche, F.; Olesen, F.; Hulley, G. Validation of remotely sensed surface temperature over an oakwood landscape-The problem of viewing and illumination geometries. Remote Sens. Environ. 2014, 148. doi:10.1016/j.rse.2014.03.016.

26. Freitas, S.C.; Trigo, I.F.; Bioucas-Dias, J. Quantifying the Uncertainty of Land Surface Temperature Retrievals From SEVIRI/Meteosat. IEEE Trans. Geos. Remote Sen. 2010, 48. doi:10.1109/TGRS.2009.2027697.

27. Berrisford, P.; Dee, D.P.; Poli, P.; Brugge, R.; Fielding, M.; Fuentes, M.; Kallberg, P.W.; Kobayashi, S.; Uppala, S.; Simmons, A. The ERA-Interim Archive Version 2.0; Technical Report; ECMWF: Shinfield Park, Reading, UK, 2011.

28. Trigo, I.F.; Boussetta, S.; Viterbo, P.; Balsamo, G.; Beljaars, A.; Sandu, I. Comparison of model land skin temperature with remotely sensed estimates and assessment of surface-atmosphere coupling. J. Geophy. Res. 2015, 120. doi:10.1002/2015JD023812.

29. Waliser, D.E.; Gautier, C. A satellite-derived climatology of the ITCZ. J. Clim. $1993,6$. doi:10.1080/01431161.2012.716532.

30. Nicholson, S.E.; Grist, J.P. The seasonal evolution of the atmospheric circulation over west Africa and Equatorial Africa. J. Clim. 2003, 16. doi:10.1175/BAMS-D-16-0287.1.

31. Nicholson, S.E. The ITCZ and the seasonal cycle over equatorial Africa. Am. Meteorol. Soc. $2017,6$. doi:10.1175/BAMS-D-16-0287.1.

32. Betts, A.K.; Ball, J.H.; Viterbo, P.; Dai, A.; Marengo, J. Hydrometeorology of the Amazon in ERA-40. J. Hydromet. 2005, 6. doi:10.1016/j.rse.2014.08.013.

33. Jiménez, C.; Prigent, C.; Catherinot, J.; Rossow, W.; Liang, P.; Moncet, J. A comparison of ISCCP land surface temperature with other satellite and in situ observations. J. Geophys. Res. 2012, 117. doi:10.1029/2011JD017058.

34. Martin, M.; Gottsche, F.M. Satellite LST Validation Report; Technical Report; ESA GlobTemperature Consortium; KIT: Bremerhaven, Germany, 2016.

35. Li, S.; Yu, Y.; Sun, D.; Tarpley, D. Evaluation of 10 year AQUA/MODIS land surface temperature with SURFRAD observations. Int. J. Remote Sens. 2014, 35. doi:10.1109/JSTARS.2015.2441096.

36. Guillevic, P.C.; Biard, J.C.; Hulley, G.C.; Privette, J.L.; Hook, S.J.; Olioso, A.; Göttsche, F.M.; Radocinski, R.; Román, M.O.; Yu, Y.; et al. Validation of Land Surface Temperature products derived from the Visible Infrared Imaging Radiometer Suite (VIIRS) using ground-based and heritage satellite measurements. Remote Sens. Environ. 2014, 154. doi:10.1016/j.rse.2014.08.013.

37. Seemann, S.W.; Borbas, E.E.; Knuteson, R.O.; Stephenson, G.R.; Huang, H.L. Development of a Global Infrared Land Surface Emissivity Database for Application to Clear Sky Sounding Retrievals from Multi-spectral Satellite Radiance Measurements. J. Geophy. Res. 2008, 47. doi:10.1109/JSTARS.2015.2441096. 
38. Wang, K.; Liang, S. Evaluation of ASTER and MODIS land surface temperature and emissivity products using long-term surface long wave radiation observations at SURFRAD sites. Remote Sens. Environ. 2009, 113. doi:10.1109/JSTARS.2015.2441096.

39. Albergel, C.; Balsamo, G.; de Rosnay, P.; Munoz-Sabater, J.; Boussetta, S. A bare ground evaporation revision in the ECMWF land-surface scheme: Evaluation of its impact using ground soil moisture and satellite microwave data. Hydrol. Earth Syst. Sci. 2012, 16. doi:10.5194/hess-16-3607-2012.

40. Johannsen, F.; Ermida, S.; Martins, J.P.A.; Trigo, I.F.; Nogueira, M.; Dutra, E. Cold Bias of ERA5 Summertime Daily Maximum Land Surface Temperature over Iberian Peninsula. Remote Sens. 2019, 11. doi: $10.3390 / \mathrm{rs} 11212570$.

41. Catalano, F.; Alessandri, A.; Felice, M.D.; Zhu, Z.; Myneni, R.B. Observationally based analysis of land-atmosphere coupling. Earth Syst. Dyn. 2016, 7. doi:10.5194/esd-7-251-2016.

42. Koster, R.D.; Sud, Y.C.; Guo, Z.; Dirmeyer, P.A.; Bonan, G.; Oleson, K.W.; Chan, E.; Verseghy, D.; Cox, P.; Davies, H.; et al. GLACE: The global land-atmosphere coupling experiment. Part I: Overview. J. Hydrometeorol. 2006, 7. doi:10.1175/JHM511.1.

43. Mitchell, K.; Lohmann, D.; Houser, P.R. Wood, E.; Schaake, J.C; Robock, A.; Cosgrove, B.A.; Sheffield, J.; Duan, Q. Luo, L; et al. The Multiple-institution North America Land Assimilation System(NLDAS): Utilising multiple GCIP products and partners in a continental distributed hydrological modelling system. J. Geophys. Res. 2004, 109. doi:10.1029/2003JD003823.

44. Zeng, X.; Wang, A. Consistent parameterization of roughness length and displacement height for sparse and dense canopies in land models. J. Hydromet. 2007, 8. doi:10.1175/JHM607.1.

45. Zheng, W.; Wei, H.; Wang, Z.; Zeng, X.; Meng, J.; Mitchelle, M.; Derber, J. Improvement of daytime land surface skin temperature over arid regions in the NCEP GFS model and its impact on satellite data assimilation. J. Geophys. Res. 2014, 14. doi:10.1029/2011JD015901.

46. Zhang, D.; Velde, R.V.D.; Su, Z.; Booij, M.J.; Hoekstra, A.Y. Assessment of roughness length schemes implemented within the Noah land surface model for high-altitude regions. J. Hydromet. 2014, 14. doi:10.1175/JHM-D-13-0102.1.

47. Zhou, Y.; Sun, X.; Ju, W.; Wen, X.; Guan, D. Seasonal, Diurnal and Wind-Direction-Dependent Variations of the Aerodynamic Roughness Length in Two Typical Forest Ecosystems of China. Terr. Atmos. Ocean Sci. 2012, 23. doi:10.3319/TAO.2011.10.06.01(A).

48. Park, S.J.; Park, S.; Ho, C.H. Roughness Length of Water Vapor over Land Surfaces and Its Influence on Latent Heat Flux. Terr. Atmos. Ocean Sci. 2009, 21. doi:10.3319/TAO.2009.11.13.01.

49. Pitman, A.J. Assessing the sensitivity of a land-surface scheme to the parameter values using a single column model. J. Clim. 1994, 7. doi:10.1175/1520-0442(1994)007. 